\title{
Preliminary results of anterior lumbar interbody fusion, anterior column realignment for the treatment of sagittal malalignment
}

\author{
Pooria Hosseini, MD, ${ }^{1}$ Gregory M. Mundis Jr., MD, ${ }^{1,2}$ Robert K. Eastlack, MD, ${ }^{2}$ Ramin Bagheri, MD, ${ }^{2}$ \\ Enrique Vargas, MD, ${ }^{3}$ Stacie Tran, MPH, ${ }^{1}$ and Behrooz A. Akbarnia, MD ${ }^{1}$
}

${ }^{1}$ San Diego Spine Foundation, San Diego; ' 2 Department of Orthopaedic Surgery, Scripps Clinic Torrey Pines, La Jolla, California; and ${ }^{3}$ Department of Orthopedics, Centro Medico Puerta de Hierro, Zapopan, Jalisco, Mexico

\begin{abstract}
OBJECTIVE Sagittal malalignment decreases patients' quality of life and may require surgical correction to achieve realignment goals. High-risk posterior-based osteotomy techniques are the current standard treatment for addressing sagittal malalignment. More recently, anterior lumbar interbody fusion, anterior column realignment (ALIF ACR) has been introduced as an alternative for correction of sagittal deformity. The objective of this paper was to report clinical and radiographic results for patients treated using the ALIF-ACR technique.
\end{abstract}

METHODS A retrospective study of 39 patients treated with ALIF ACR was performed. Patient demographics, operative details, radiographic parameters, neurological assessments, outcome measures, and preoperative, postoperative, and mean 1-year follow-up complications were studied.

RESULTS The patient population comprised 39 patients ( 27 females and 12 males) with a mean follow-up of $13.3 \pm$ 4.7 months, mean age of $66.1 \pm 11.6$ years, and mean body mass index of $27.3 \pm 6.2 \mathrm{~kg} / \mathrm{m}^{2}$. The mean number of ALIF levels treated was $1.5 \pm 0.5$. Thirty-three (84.6\%) of 39 patients underwent posterior spinal fixation and $33(84.6 \%)$ of 39 underwent posterior column osteotomy, of which $20(60.6 \%)$ of 33 procedures were performed at the level of the ALIF ACR. Pelvic tilt, sacral slope, and pelvic incidence were not statistically significantly different between the preoperative and postoperative periods and between the preoperative and 1-year follow-up periods (except for PT between the preoperative and 1-year follow-up, $p=0.018$ ). Sagittal vertical axis, T-1 spinopelvic inclination, lumbar lordosis, pelvic incidence-lumbar lordosis mismatch, intradiscal angle, and motion segment angle all improved from the preoperative to postoperative period and the preoperative to 1-year follow-up $(p<0.05)$. The changes in motion segment angle and intradiscal angle achieved in the ALIF-ACR group without osteotomy compared with the ALIF-ACR group with osteotomy at the level of ACR were not statistically significant. Total visual analog score, Oswestry Disability Index, and Scoliosis Research Society-22 scores all improved from preoperative to postoperative and preoperative to 1-year follow-up. Fourteen patients (35.9\%) experienced 26 complications (15 major and 11 minor). Eleven patients required reoperation. The most common complication was proximal junctional kyphosis (6/26 complications, 23\%) followed by vertebral body/ endplate fracture $(3 / 26,12 \%)$.

CONCLUSIONS This study showed satisfactory radiographic and clinical outcomes at the 1-year follow-up. Proximal junctional kyphosis was the most common complication followed by fracture, complications that are commonly associated with sagittal realignment surgery and may not be mitigated by the anterior approach.

https://thejns.org/doi/abs/10.3171/2017.8.FOCUS17423

KEY WORDS minimally invasive surgery; ALIF; ACR; anterior lumbar interbody fusion; anterior column realignment; pelvic parameters; outcome measures; fusion grade; complications 
$\mathrm{R}$ ESTORATION of sagittal balance has been directly linked to satisfactory postsurgical outcomes as demonstrated by health-related quality of life data after adult spinal deformity (ASD) surgery. Even mild sagittal malalignment has been associated with a decline in quality of life..$^{5,710}$ In addition, it has been shown that the severity of symptoms increases in a linear fashion with progressive sagittal malalignment. ${ }^{7}$ Realignment objectives for sagittal plane correction independent of surgical technique have been defined as pelvic tilt $(\mathrm{PT})<20^{\circ}$, sagittal vertical axis (SVA) $<50 \mathrm{~mm}, \mathrm{~T}-1$ spinopelvic inclination $(\mathrm{T} 1 \mathrm{SPI})<0^{\circ}$, and lumbar lordosis $(\mathrm{LL})=$ pelvic incidence (PI) $\pm 10^{\circ} .{ }^{17}$ More recently, however, Lafage et al. ${ }^{9}$ showed that these sagittal spinopelvic alignment goals vary with age. Thus, operative alignment targets should account for age, with younger patients requiring different target objectives than older patients.

Achieving realignment objectives when treating more severe kyphotic deformities has traditionally been accomplished through posterior approaches using osteotomies. Although effective in correcting relative kyphosis, these techniques are associated with prolonged operative times, neurological complications, and a high volume of blood loss. $2,6,8$ To mitigate shortfalls associated with these conventional techniques, minimally invasive (MI) lateral lumbar interbody fusion (LLIF) with anterior longitudinal ligament (ALL) release was introduced. ${ }^{2}$ The concept of using hyperlordotic anterior grafts with or without posterior release has been termed anterior column realignment (ACR) and has been shown to be a viable option for correction of focal sagittal plane deformity. ${ }^{2,15}$ In this article, we describe the technique of a wide anterior release through a retroperitoneal anterior approach for interbody fusion. ACR is not proposed to eliminate the need for posterior osteotomies, but the ACR technique may more aptly restore spinopelvic parameters and potentially reduce the need for 3-column osteotomies. ${ }^{12}$ Recently, it has been suggested that radiographic outcomes are improved if the lumbar lordosis can be restored to anatomical segmental relationships. ${ }^{11}$ Lower lumbar segments are the focus of a majority of anterior lumbar interbody fusion (ALIF)-ACR surgeries.

One of the limitations to the LLIF technique is the accessibility to L5-S1, which is arguably the most important site of lordosis restoration as it represents the foundation for the remainder of the spine.${ }^{11}$ Traditional ALIF implants offer $0^{\circ}-15^{\circ}$ of lordosis, which, if combined with posterior osteotomies, can result in greater correction. In patients who require a greater degree of lordosis, ALIF has historically been achieved using femoral ring allograft along with cutting custom angles or by using more invasive posterior-based osteotomy techniques. To date, there has only been 1 report on ALIF ACR. ${ }^{16}$ In the current study, we aimed to evaluate the clinical and radiographic outcomes with ALIF ACR for sagittal plane spinal deformities. The aim of this study was to report both radiographic and clinical outcomes among patients who were treated with an ALIF ACR for adult sagittal plane deformity.

\section{Methods}

\section{Study Design}

A retrospective study with IRB approval was performed in 50 patients treated with ALIF ACR by 3 surgeons at 2 centers between 2013 and 2015. Patients were eligible for study inclusion if they 1) were treated for ASD with ALIF ACR, and 2) had radiographic follow-up at an average of 1 year postoperatively. In this manner, 39 patients were included, and 11 patients were excluded due to missing radiographic data. An independent observer studied patients' radiographic and clinical records. Spinal measurements were obtained at preoperative, postoperative (first visit prior to 3 months), and last follow-up time points.

Demographic data included age at the time of surgery, sex, diagnosis, body mass index, and length of follow-up. Operative details included a history of prior spine surgery, prior spine fusion, level of anterior longitudinal ligament release, number of ALIF levels, cage lordotic angle, anterior screw fixation, occurrence and type of posterior osteotomy, posterior spinal fixation, cage size, ALIF-ACR levels, and length of hospital stay. In addition, we aimed to obtain the preoperative blood hemoglobin level, estimated blood loss, and operating time for both the anterior and posterior parts of the operation.

\section{Surgical Technique}

The patient was positioned supine on the operating room table. With the aid of a vascular surgeon, an anterior retroperitoneal approach was followed to the anterior lumbar spine. After confirmation of levels, an annulotomy was made. Cobb elevators were used to denude the endplates of cartilaginous material. The dissection was carried posterior to the posterior longitudinal ligament. Next the annulus dissection was carried laterally and the annulus released, followed by release of the posterior longitudinal ligament. Using a series of trials, the appropriately sized implant was selected. During this process, it is necessary to keep in mind the surgical goals to achieve realignment, allow for foraminal decompression by increasing posterior disc height, and achieve bony union. Once the preplanned implant was placed, it was secured into the vertebral body with 1 or 2 screws through an integrated fixation mechanism. The angles currently offered for the interbody device are $10^{\circ}, 12^{\circ}, 15^{\circ}, 20^{\circ}$, and $30^{\circ}$, depending on the needs of the patient. Once the interbody was placed, final imaging was performed to determine if the alignment goals were achieved. It is crucial to examine the superior articulating process of the caudal vertebrae involved to see if the hyperlordotic angle has resulted in unintended foraminal compromise. If there is resultant stenosis, it is highly recommended that this facet be removed to allow for free passage of the nerves.

\section{Radiographic Parameters}

Radiographic parameters included pelvic tilt (PT), sacral slope (SS), pelvic incidence (PI), sagittal vertical axis (SVA), T-1 spinopelvic inclination (T1SPI), thoracic kyphosis, intradiscal angle (IDA), motion segment angle (MSA), lumbar lordosis (LL), and PI-LL mismatch measurements.

Fusion was graded utilizing the Lenke classification on plain radiographs as follows: Grade I, fusion with remodeling and trabeculae present; Grade II, intact graft with 
incomplete remodeling and no lucency present; Grade III, intact graft with potential lucency at the cranial or caudal end; and Grade IV, absent fusion with collapse/resorption of the graft. ${ }^{4}$

\section{Outcome Measures}

Outcome measures included assessing visual analog scale (VAS), Oswestry Disability Index (ODI), and Scoliosis Research Society-22 (SRS-22) scores. Complications were grouped into major and minor based on the complication classification of Schwab et al. ${ }^{18}$

\section{Statistical Analysis}

The Wilcoxon signed-rank test was used to assess significant differences between pre- and postoperative parameters, with significance set at $p<0.05$. All statistical analyses were done using SPSS (version 23, IBM).

\section{Results}

\section{Patient Population}

A total of 39 patients (27 females and 12 males) with a mean follow-up of $13.3 \pm 4.7$ months $( \pm \mathrm{SD}$; range 5-24 months) were studied. The mean age of the studied group was $66.1 \pm 11.6$ years (range $34-85$ years). The mean body mass index was $27.3 \pm 6.2 \mathrm{~kg} / \mathrm{m}^{2}$ (range $\left.16-44 \mathrm{~kg} / \mathrm{m}^{2}\right)$.

\section{Operative Details}

Nineteen (49\%) of the 39 patients had undergone prior spine surgery. A total of 60 ALIF-ACR levels were treated in 39 patients (mean 1.53 levels per patient; range 1-2 levels). Eighteen patients (46\%) underwent 1-level ALIF ACR and 21 patients (54\%) underwent 2-level ALIF ACR. A total of 36 levels $(60 \%)$ were treated at L5-S1, and 24 levels (40\%) were treated at L4-5. All ALIF-ACR cages were supplemented with anterior plate or integrated fixation. Twelve (20\%) of 60 ALIF-ACR levels had same-level posterior column osteotomies. Forty-four (73\%) of $60 \mathrm{lev}-$ els were treated with posterior spinal fixation in addition to their ALIF-ACR procedure, and 16 levels (27\%) received standalone ALIF ACR. The mean hospital stay after ALIF ACR combined with additional single-staged or 2-staged operations was 7.2 \pm 4.1 days (range 2-17 days).

\section{Radiographic Parameters}

PT, SS, and PI values were not statistically different from the preoperative to postoperative period and the preoperative to 1-year follow-up, with the exception of PT from the preoperative to 1-year follow-up $(\mathrm{p}=0.018)$. SVA, T1SPI, LL, PI-LL mismatch, IDA, and MSA all improved from preoperative to postoperative and preoperative to 1-year follow-up, and the improvement was statistically significant $(\mathrm{p}<0.05)$ (Table 1$)$.

\section{Fusion Grades}

Thirty-seven (95\%) of 39 patients had Grade I or Grade II fusion at their latest follow-up and the remaining 2 patients $(5 \%)$ had Grade III or Grade IV fusion.

\section{Outcome Measures}

All outcome measures (VAS, ODI, and SRS-22 scores) improved from the preoperative to postoperative period and preoperative to 1-year follow-up, and all improvements were statistically significant (Table 2).

\section{Complications}

Fourteen of 39 patients (35.9\%) experienced 26 complications (major 15, minor 11). Of the 39 patients, 11 required reoperation. The most common complication was proximal junctional kyphosis $(6 / 26,23 \%)$ followed by vertebral body/endplate fracture $(3 / 26,12 \%)$. The breakdown of the complications is provided in Table 3 .

\section{Neurological Assessment}

Preoperatively, 15 of 39 patients had abnormal lowerextremity sensation, and all 15 patients had resolution in paresthesia at the final follow-up. There were 2 cases of new onset thigh and leg numbness, with 1 case resolving

TABLE 1. Radiographic measures

\begin{tabular}{|c|c|c|c|c|c|c|c|}
\hline \multirow{2}{*}{$\begin{array}{c}\text { Radiographic } \\
\text { Measure }\end{array}$} & \multicolumn{7}{|c|}{ Value } \\
\hline & Preop & Postop & $\Delta^{*}$ & $p$ & $1 \mathrm{Yr}$ & $\Delta \dagger$ & $p$ \\
\hline PT $\left({ }^{\circ}\right)$ & $25.5 \pm 12.1$ & $21.6 \pm 10.4$ & 3.9 & 0.088 & $21.7 \pm 9$ & 3.8 & 0.018 \\
\hline $\operatorname{SS}\left({ }^{\circ}\right)$ & $31.5 \pm 10.1$ & $34.9 \pm 10.3$ & 3.4 & 0.057 & $29.1 \pm 7.3$ & 2.4 & 0.085 \\
\hline $\mathrm{PI}\left({ }^{\circ}\right)$ & $56 \pm 14.6$ & $56.9 \pm 13.5$ & 0.9 & 0.818 & $52 \pm 10.6$ & 4.0 & 0.091 \\
\hline SVA (cm) & $7.9 \pm 4.7$ & $3.4 \pm 4.8$ & 4.5 & $<0.001$ & $2.4 \pm 2.4$ & 5.5 & $<0.001$ \\
\hline T1SPI $\left({ }^{\circ}\right)$ & $0.8 \pm 5.2$ & $-2.1 \pm 3.6$ & 2.9 & 0.005 & $-2.4 \pm 3.9$ & 3.2 & 0.007 \\
\hline $\mathrm{TK}\left({ }^{\circ}\right)$ & $28.6 \pm 19.7$ & $38.4 \pm 15.6$ & 9.8 & 0.02 & $32.4 \pm 25$ & 6.0 & 0.296 \\
\hline $\operatorname{LL}\left({ }^{\circ}\right)$ & $-34.9 \pm 22.6$ & $-47.6 \pm 25.7$ & 12.7 & 0.008 & $-48.8 \pm 10.3$ & 13.9 & 0.001 \\
\hline PI-LL $\left({ }^{\circ}\right)$ & $22.8 \pm 17.3$ & $10.6 \pm 8.1$ & 12.2 & $<0.001$ & $9.5 \pm 6.6$ & 10.6 & $<0.001$ \\
\hline $\operatorname{IDA}\left({ }^{\circ}\right)$ & $-6 \pm 5.6$ & $-22.1 \pm 5.8$ & 16.1 & $<0.001$ & $-20.8 \pm 5.6$ & 14.8 & $<0.001$ \\
\hline $\operatorname{MSA}\left({ }^{\circ}\right)$ & $-12.4 \pm 14.7$ & $-30.6 \pm 8.7$ & 18.2 & $<0.001$ & $-28.6 \pm 7.1$ & 16.2 & $<0.001$ \\
\hline
\end{tabular}

TK = thoracic kyphosis.

Mean values are presented as the mean \pm SD.

* Change from preoperative to postoperative.

$\dagger$ Change from preoperative to 1 -year follow-up. 
TABLE 2. Outcome measures

\begin{tabular}{lcccccrrr}
\hline & \multicolumn{7}{c}{ Value } \\
\cline { 2 - 8 } Outcome Measure & Preop & Postop & $\Delta^{*}$ & $\mathrm{p}$ & $1 \mathrm{Yr}$ & $\Delta \dagger$ & $\mathrm{p}$ \\
\hline VAS & $6.8 \pm 1.9$ & $3 \pm 2$ & 3.8 & $<0.001$ & $2.1 \pm 2$ & 4.7 & $<0.001$ \\
\hline ODI & $54 \pm 16$ & $38 \pm 16$ & 16.0 & $<0.001$ & $26 \pm 14$ & 28.0 & $<0.001$ \\
\hline SRS-22 & $2.3 \pm 0.56$ & $3.3 \pm 0.57$ & 1.0 & 0.003 & $3.7 \pm 0.38$ & 1.4 & 0.018 \\
\hline $\begin{array}{l}\text { Mean values are presented as the mean } \pm \text { SD. } \\
\text { * Change from preoperative to postoperative. } \\
\dagger \text { Change from preoperative to 1-year follow-up. }\end{array}$ & & & & & & \\
\end{tabular}

at final follow-up (Case 28) and one patient with persistent paresthesia (Case 18). Ten (26\%) of 39 patients had abnormal lower-limb strength preoperatively. Seven of these 10 patients recovered full strength and 3 remained at baseline with no further surgical intervention at most recent follow-up. There were no occurrences of sympathetic dysfunction or retrograde ejaculation. Figures 1 and 2 provide examples of patients treated with ALIF ACR in this study.

\section{Discussion}

This is a retrospective review of 39 patients treated with ALIF ACR, with a mean follow-up of 13.3 months. SVA, T1SPI, LL, PI-LL mismatch, IDA, and MSA significantly improved from pre- to postoperative and preoperative to 1-year follow-up ( $\mathrm{p}<0.05)$, and PT improved from preoperative to 1-year follow-up. Similarly, health-related quality of life measures (VAS, ODI, and SRS-22 scores) significantly improved at the most recent follow-up time point. Fusion grade was satisfactory at the latest follow-up, with 95\% of patients being in Grades I and II.

In the only published report on the ALIF-ACR technique by Saville et al. ${ }^{16}$ on 69 hyperlordotic cages in 41 patients, the authors showed improvement in the overall mean lumbar lordosis (from $39^{\circ}$ to $59^{\circ}, \mathrm{p}<0.01$ ) and mean SVA (from $113 \mathrm{~mm}$ to $43 \mathrm{~mm}$ ). The results of the current study are in line with the radiographic findings of Saville et al. The authors also reported a $20 \%$ overall complication rate. The lower complication rate in that report compared with our results might be due to the longer follow-up in our study or a more extensive consideration of complications, such as inclusion of minor medical complications. The only other available reports on the ACR technique are focused on laterally based ACR application (LLIF ACR).

Despite the perception that MI lumbar interbody fusion procedures are unable to affect segmental and regional lordosis, a literature review by Uribe et al. ${ }^{20}$ showed that significant gains in both weighted average LL and segmental lordosis occur following MI interbody fusion. The changes in LL in the current study are in full support of the findings of Uribe et al. These results suggest that MI approaches are able to impact regional and local segmental alignment.

In another study on LLIF ACR, Murray et al. ${ }^{13}$ showed that radiographic parameters, including LL, PT, and SVA, improved from preoperatively to the latest follow-up. Similarly, Turner et al. ${ }^{19}$ reported improvement in LL, T1SPI, and IDA utilizing the LLIF-ACR technique. All of these radiographic outcomes are consistent with our findings with ALIF ACR.

In terms of complications, Murray et al. ${ }^{13}$ reported 1 case of retrograde ejaculation after LLIF-ACR surgery. Within our current ALIF-ACR, study there were no cases of retrograde ejaculation. Berjano et al. ${ }^{3}$ experienced 1 case of bowel perforation in their LLIF-ACR study, and

TABLE 3. Complications

\begin{tabular}{|c|c|c|c|}
\hline $\begin{array}{l}\text { Case } \\
\text { No. }\end{array}$ & Complication & Treatment & $\begin{array}{l}\text { Complication } \\
\text { Type }\end{array}$ \\
\hline \multirow[t]{2}{*}{1} & UTI & Medical & Minor \\
\hline & Bilat leg swelling & Medical & Minor \\
\hline 3 & Wound dehiscence & Surgical & Major \\
\hline 12 & ASD & Surgical & Major \\
\hline \multirow[t]{2}{*}{15} & PJK & Surgical & Major \\
\hline & DVT & Medical & Minor \\
\hline 16 & PJK & Surgical & Major \\
\hline 18 & $\begin{array}{l}\text { Decreased postop L4-S1 } \\
\text { sensation }\end{array}$ & Conservative & Minor \\
\hline \multirow[t]{2}{*}{20} & Screw loosening & Surgical & Major \\
\hline & PJK & Surgical & Major \\
\hline 23 & PJK & Surgical & Major \\
\hline 28 & Hematoma & Surgical & Major \\
\hline \multirow[t]{4}{*}{32} & PJK & Surgical & Major \\
\hline & VB fracture & Surgical & Major \\
\hline & Encephalopathy & Medical & Minor \\
\hline & lleus & Medical & Minor \\
\hline 36 & lleus & Medical & Minor \\
\hline \multirow[t]{6}{*}{37} & Screw loosening & Surgical & Major \\
\hline & End plate fracture & Surgical & Major \\
\hline & PJK & Surgical & Major \\
\hline & Renal failure & Medical & Minor \\
\hline & Acute transaminitis & Medical & Minor \\
\hline & Respiratory tract infection & Medical & Minor \\
\hline 38 & VB fracture & Surgical & Major \\
\hline \multirow[t]{2}{*}{39} & Deep surgical site infection & Surgical & Major \\
\hline & UTI & Medical & Minor \\
\hline
\end{tabular}

DVT = deep venous thrombosis; PJK = proximal junctional kyphosis; UTI = urinary tract infection; $\mathrm{VB}=$ vertebral body. 


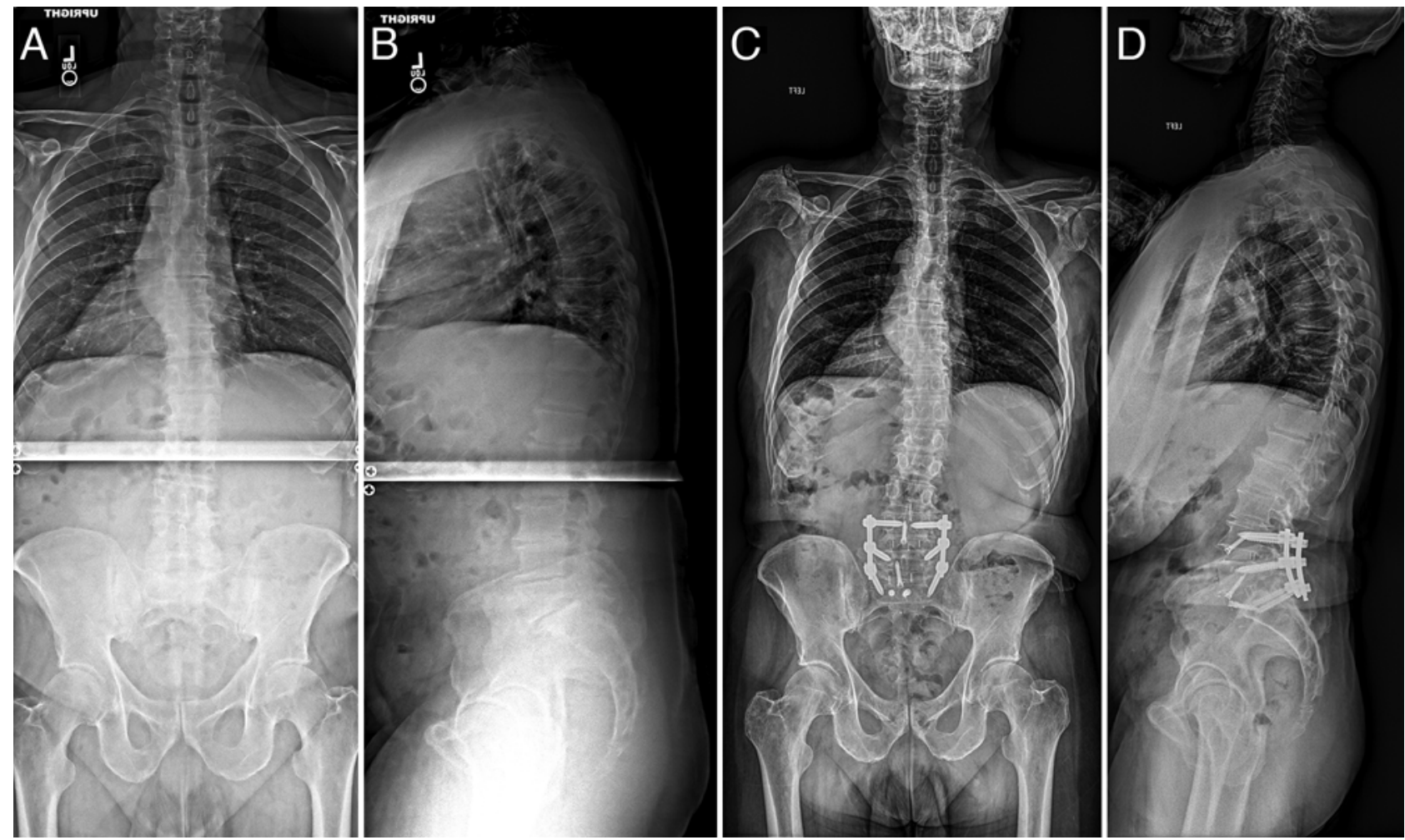

FIG. 1. Images obtained in a 72-year-old male patient with symptomatic spondylolisthesis at L5-S1 and radiculopathy of L-4 and L-5 with complaints of stooped forward posture with activity. A and B: Preoperative anteroposterior (AP; A) and lateral (B) radiographs revealing a PI of $59^{\circ}$, $\mathrm{LL}$ of $35^{\circ}$, LL-PI of $24^{\circ}, \mathrm{PT}$ of $27^{\circ}$, SVA of $112 \mathrm{~mm}$, and L4-S1 of $30^{\circ}$. C and D: Postoperative AP (C) and lateral (D) radiographs obtained in the same patient who was treated with ALIF ACR at L4-S1 and posterior fusion at the same levels. Postoperatively, the values changed to a PI of $61^{\circ}$, LL of $60^{\circ}$, LL-PI of $1^{\circ}, \mathrm{PT}$ of $23^{\circ}$, SVA of $8 \mathrm{~mm}$, and L4-S1 of $61^{\circ}$.
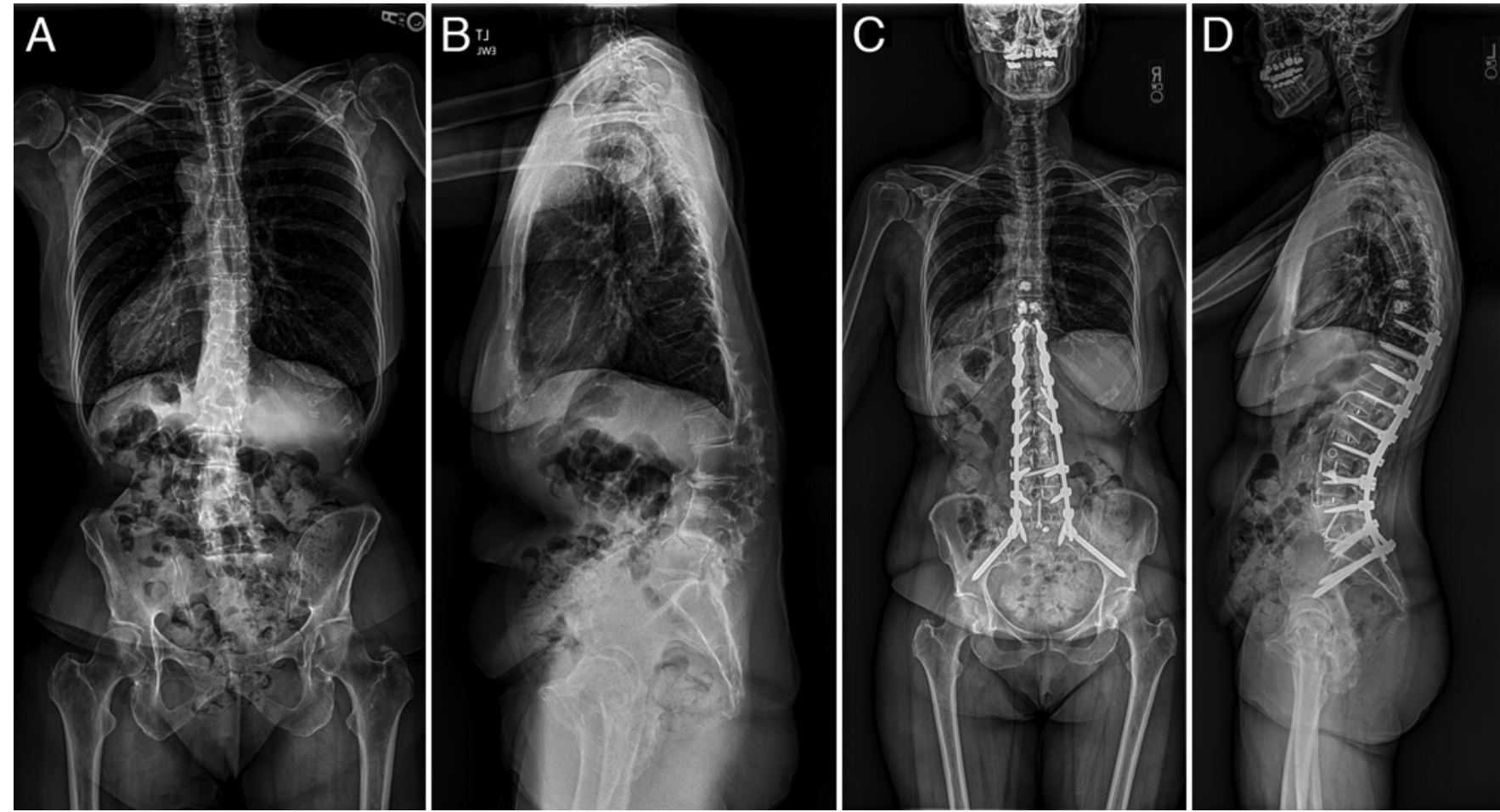

FIG. 2. A and B: Preoperative AP (A) and lateral (B) radiographs obtained in a 68-year-old female patient with lumbar spondylolisthesis and thoracolumbar kyphoscoliosis. $C$ and D: Postoperative AP and lateral radiographs obtained in the same patient who was treated with ALIF ACR at L5-S1, LLIF at L1-5, posterior fusion at T-10 to pelvis, and Smith-Petersen osteotomy at L1-3. 
Akbarnia et al. ${ }^{2}$ reported 1 case of vascular injury during anterior plate removal in their LLIF ACR. Neither of these complications occurred after ALIF ACR in our study. Most recently, Aichmair et al. ${ }^{1}$ reported the results of single-level LLIF in 52 patients with a mean follow-up of 16.1 months (range 5-44 months). The reoperation rate in that study was $21.2 \%$ (11/52 patients). Our reoperation rate at the beginning of our learning curve for ALIF ACR was somewhat similar (28.2\%, 11/39 patients).

MI techniques have been proposed to decrease morbidity associated with more conventional techniques, including posterior osteotomies. There has been some discussion that the ALIF-ACR technique might be powerful enough to replace posterior-based 3-column osteotomies. Mundis et al. ${ }^{12}$ recently published their results comparing LLIF ACR and pedicle subtraction osteotomy, and demonstrated similar radiographic results as pedicle subtraction osteotomy in a matched cohort with significantly less estimated blood loss and similar overall complication rates. In our current study of 39 patients treated with ALIF ACR only, $12(20 \%)$ of 60 levels were treated with additional posterior osteotomy surgery to achieve desired alignment goals. The goal of this study, however, was not to investigate this technique as a replacement of a posterior-based osteotomy, but rather as a technique that has the ability to restore the appropriate segmental alignment required to get the desired global realignment.

Finally, health-related quality of life measures have been shown to improve considerably following LLIF ACR. We found improvements similar to those of Pimenta et al., ${ }^{14}$ following ALIF-ACR application.

There are limitations to this study. First, fusion grades were assessed on plain radiographic images because CT images were not available for all cases. Second, smoking status and bone quality score at the time of surgery might be contributory factors with respect to outcome measures and fusion results. Data related to these 2 factors were not adequately captured in this study. Future studies with larger numbers of patients and patients being treated farther along the learning curve of performing ALIF ACR will likely allow for a more precise determination of its capacity and limitations.

\section{Conclusions}

We believe that the ALIF ACR is a valuable complement to other realignment techniques for sagittal plane deformities. This is particularly true at the lower levels of the lumbar spine (L4-S1), where the direct lateral approach (LLIF ACR) might not be feasible. All improvements in radiographic parameter appeared to be similar or even superior to other ALIF-ACR and LLIF-ACR reports. ALIF ACR was sufficiently capable of significantly improving all studied health-related quality of life measures (VAS, ODI, and SRS-22 scores). ALIF ACR also has its own unique complication profile that must be carefully addressed with careful patient selection and refinement of the technique.

\section{References}

1. Aichmair A, Alimi M, Hughes AP, Sama AA, Du JY, Härtl
$\mathrm{R}$, et al: Single-level lateral lumbar interbody fusion for the treatment of adjacent segment disease: a retrospective twocenter study. Spine (Phila Pa 1976) 42:E515-E522, 2017

2. Akbarnia BA, Mundis GM Jr, Moazzaz P, Kabirian N, Bagheri R, Eastlack RK, et al: Anterior column realignment (ACR) for focal kyphotic spinal deformity using a lateral transpsoas approach and ALL release. J Spinal Disord Tech 27:29-39, 2014

3. Berjano P, Cecchinato R, Sinigaglia A, Damilano M, Ismael MF, Martini C, et al: Anterior column realignment from a lateral approach for the treatment of severe sagittal imbalance: a retrospective radiographic study. Eur Spine J 24 (Suppl 3):433-438, 2015

4. Bridwell KH, Lenke LG, McEnery KW, Baldus C, Blanke K: Anterior fresh frozen structural allografts in the thoracic and lumbar spine. Do they work if combined with posterior fusion and instrumentation in adult patients with kyphosis or anterior column defects? Spine (Phila Pa 1976) 20:1410-1418, 1995

5. Djurasovic M, Glassman SD: Correlation of radiographic and clinical findings in spinal deformities. Neurosurg Clin $\mathbf{N}$ Am 18:223-227, 2007

6. Dorward IG, Lenke LG: Osteotomies in the posterior-only treatment of complex adult spinal deformity: a comparative review. Neurosurg Focus 28(3):E4, 2010

7. Glassman SD, Bridwell K, Dimar JR, Horton W, Berven S, Schwab F: The impact of positive sagittal balance in adult spinal deformity. Spine (Phila Pa 1976) 30:2024-2029, 2005

8. Hyun SJ, Rhim SC: Clinical outcomes and complications after pedicle subtraction osteotomy for fixed sagittal imbalance patients: a long-term follow-up data. J Korean Neurosurg Soc 47:95-101, 2010

9. Lafage R, Schwab F, Challier V, Henry JK, Gum J, Smith J, et al: Defining spino-pelvic alignment thresholds: should operative goals in adult spinal deformity surgery account for age? Spine (Phila Pa 1976) 41:62-68, 2016

10. Lafage V, Schwab F, Patel A, Hawkinson N, Farcy JP: Pelvic tilt and truncal inclination: two key radiographic parameters in the setting of adults with spinal deformity. Spine (Phila Pa 1976) 34:E599-E606, 2009

11. Lamartina C, Berjano P: Classification of sagittal imbalance based on spinal alignment and compensatory mechanisms. Eur Spine J 23:1177-1189, 2014

12. Mundis GM Jr, Turner JD, Kabirian N, Pawelek J, Eastlack RK, Uribe J, et al: Anterior column realignment has similar results to pedicle subtraction osteotomy in treating adults with sagittal plane deformity. World Neurosurg 105:249256, 2017

13. Murray G, Beckman J, Bach K, Smith DA, Dakwar E, Uribe JS: Complications and neurological deficits following minimally invasive anterior column release for adult spinal deformity: a retrospective study. Eur Spine J 24 (Suppl 3):397-404, 2015

14. Pimenta L, Fortti F, Oliveira L, Marchi L, Jensen R, Coutinho E, et al: Anterior column realignment following lateral interbody fusion for sagittal deformity correction. Eur J Orthop Surg Traumatol 25 (Suppl 1):S29-S33, 2015

15. Saigal R, Mundis GM Jr, Eastlack R, Uribe JS, Phillips FM, Akbarnia BA: Anterior column realignment (ACR) in adult sagittal deformity correction: technique and review of the literature. Spine (Phila Pa 1976) 41 (Suppl 8):S66-S73, 2016

16. Saville PA, Kadam AB, Smith HE, Arlet V: Anterior hyperlordotic cages: early experience and radiographic results. J Neurosurg Spine 25:713-719, 2016

17. Schwab F, Patel A, Ungar B, Farcy JP, Lafage V: Adult spinal deformity-postoperative standing imbalance: how much can you tolerate? An overview of key parameters in assessing alignment and planning corrective surgery. Spine (Phila Pa 1976) 35:2224-2231, 2010 
18. Schwab FJ, Hawkinson N, Lafage V, Smith JS, Hart R, Mundis $\mathrm{G}$, et al: Risk factors for major peri-operative complications in adult spinal deformity surgery: a multi-center review of 953 consecutive patients. Eur Spine J 21:2603-2610, 2012

19. Turner JD, Akbarnia BA, Eastlack RK, Bagheri R, Nguyen S, Pimenta L, et al: Radiographic outcomes of anterior column realignment for adult sagittal plane deformity: a multicenter analysis. Eur Spine J 24 (Suppl 3):427-432, 2015

20. Uribe JS, Myhre SL, Youssef JA: Preservation or restoration of segmental and regional spinal lordosis using minimally invasive interbody fusion techniques in degenerative lumbar conditions: a literature review. Spine (Phila Pa 1976) 41 (Suppl 8):S50-S58, 2016

\section{Disclosures}

The authors report the following. Dr. Mundis: consultant for NuVasive and K2M. Dr. Eastlack: consultant for NuVasive, Alphatec, Seaspine, Aesculap, and Titan; ownership in NuVasive; direct stock ownership in Alphatec and Seaspine; and patent holder with Globus Medical, Titan, NuTech, Invuity, and Spine Innovation. Dr. Bagheri: consultant for NuVasive Spine. Dr. Akbarnia: consultant for NuVasive and $\mathrm{K} 2 \mathrm{M}$; direct stock ownership in NuVasive and NociMed; and royalties from NuVasive, K2M, and DePuy Spine.

\section{Author Contributions}

Conception and design: Mundis, Hosseini, Akbarnia. Acquisition of data: Hosseini, Vargas. Analysis and interpretation of data: Hosseini. Drafting the article: Mundis, Hosseini. Critically revising the article: Mundis, Eastlack, Bagheri, Vargas, Akbarnia. Reviewed submitted version of manuscript: Mundis, Hosseini, Eastlack, Bagheri, Tran, Akbarnia. Approved the final version of the manuscript on behalf of all authors: Mundis. Statistical analysis: Tran. Administrative/technical/material support: Eastlack, Bagheri. Study supervision: Mundis.

\section{Supplemental Information Videos}

Video Abstract. https://vimeo.com/240986868.

\section{Correspondence}

Gregory M. Mundis Jr., Scripps Clinic Torrey Pines, 10666 N Torrey Pines Rd., La Jolla, CA 92037. email: gmundis1@ gmail.com. 